\title{
"Quantitative Criteria for Adequacy of Academic Library Collections"': A Reprint of a CERL Classic
}

In the 1930 s the regional accrediting associations gave up trying to determine the minimum number of volumes an academic library should have on its shelves before its parent institution would be accreditable. While most academic librarians agreed with the associations' new-found principle that "an institution's resources must be judged in terms of its program," this guideline proved difficult for most of us to use in our day-to-day collection development work. Surely, we felt, there must be some number of volumes below which a college library collection would be unarguably of insufficient size. Planners moreover pressed us for hard numbers that could be used for budgetary purposes and for long-range institutional development. If we librarians would not (or could not) provide them, we were assured, institutional planners would develop them for themselves. Yet we librarians had difficulty finding consensus among us as to what an appropriate number of volumes would be for a library.

In the years before and after World War II we did at least begin to build lists of books that we felt should be found in almost any college collection. That experience led us in 1959 to adopt in ACRL's first set of college library standards the figure of 50,000 as the minimum number of volumes that every college library should own. Almost immediately, however, we were dissatisfied with that figure as well, not because we felt it was in the wrong "ballpark," but rather primarily because it obviously did not take individual insti- tutional uniquenesses into account. Also, it was too "round." "Why 50,000?" we asked. "Why not 49,624 ?" Or almost any other number of that approximate magnitude?

In 1964 Verner W. Clapp and Robert T. Jordan were retained to advise authorities on the growth needs of state-supported academic libraries in the State of Ohio. In their effort to find hard numbers while still taking into account legitimate institutional diversities, they produced a concept that has subsequently come to bear their names as the "Clapp/Jordan Formula." A paper reporting their deliberations was published in CRL in 1965, and for a quarter of a century that paper has played a seminal role in our thinking regarding quantitative standards for academic libraries.

The original piece by Messrs. Clapp and Jordan, which appeared in the September 1965 issue of College $\mathcal{E}$ Research Libraries, is now reprinted here, incorporating the corrigenda published in the January 1966 issue, page 72. Persons who have not previously read it, or others who have forgotten it, may be surprised to find that the authors' deliberations extended far beyond a simple volume count. It is probably just as well that some of their further thoughts have been forgotten, but there may also be some overlooked considerations in this piece that could once again be usefully raised. In any case this paper should be remembered as a landmark contribution to the literature of academic librarianship.David Kaser. 